\title{
A Elegia no Canto IV da Eneida
}

The Elegy in the Aeneid Book IV

Mariana Marchini Leite Rodrigues ${ }^{1}$ e-mail: mariana.marchini.rodrigues@usp.br orcid: http://orcid.org/0000-0002-3100-6574

$\begin{array}{r}\text { Paulo Martins } \\ { }^{2}\end{array}$
e-mail: paulomar@usp.br
orcid: http://orcid.org/0000-0002-2321-1033

DOI: http://dx.doi.org/10.25187/codex.v5i2.13971

\section{Resumo:}

No Canto IV da Eneida, Virgílio parece valer-se de tópicas do gênero elegíaco ao narrar o malfadado amor entre Dido e Eneias, inserindo-as dentro do gênero épico. Algumas características fundamentais do amante elegíaco, a saber, o furor pelo qual é tomado ao ser ferido pelas flechas do Cupido, o ócio dos amantes enquanto tais, a mala fama que advém desse amor, e, por fim, a condição misera na qual o amante se encontra, diante da qual é sempre feito um lamento, mostraram-se presentes na composição poética do Canto IV. Para além, então, de demonstrar como o gênero épico, sem perder seu rigor formal, subsume outros gêneros, neste caso o elegíaco, este artigo também procura observar como esta operação acaba por servir tanto ao propósito intranarrativo como extranarrativo de Virgílio ao escrever sua Eneida. No primeiro caso, se lembrarmos que os cantos I ao VI ocupam-se da construção do $\tilde{\eta} \theta$ os heroico de Eneias, a recusa do herói em permanecer com a rainha confirma, mais uma vez, seu destino, que é a fundação de Roma, destino esse que é próprio de um herói épico - e não de um amante elegíaco. Já no segundo caso, é necessário, primeiro, ter em mente a intenção de Virgílio ao compor a Eneida, que é a inserção da história de Roma no mito, o qual, vale lembrar, é a matéria narrativa do próprio poema épico. Dessa forma, o abandono de Dido e a imprecação que a rainha realiza dos versos 590-640 é utilizada pelo poeta para justificar, ainda que ironicamente, a rivalidade e violência dos cartagineses contra os romanos nas Guerras Púnicas, colocando-as como resultado da frustração amorosa de uma mulher.

Palavras-chave: Eneida; Canto IV; Virgílio; épica; elegia; amor

\footnotetext{
${ }^{1}$ Graduanda de Letras (Latim e Português) da Universidade de São Paulo (Brasil); bolsista do Conselho Nacional de Desenvolvimento Científico e Tecnológico (CNPq), sob a orientação do Prof. Dr. Paulo Martins.

${ }^{2}$ Professor Livre-Docente do Departamento de Letras Clássicas e Vernáculas da Faculdade de Filosofia, Letras e Ciências Humanas da Universidade de São Paulo (Brasil); Pesquisador do Conselho Nacional de Desenvolvimento Científico e Tecnológico (CNPq); Visiting Professor no King's College London e Visiting Fellow na Yale University.
} 


\begin{abstract}
:
In Aeneid's book IV, Virgil makes use of elegiac topics while narrating Dido and Aeneas' ill-fated love, inserting these topics into the epic genre. Some key characteristics of elegiac lover, such as the furor by which he is taken when injured by Cupid's dart; lover's idleness; the mala fama that emerges from the love affair; and, lastly, the misera condition in which the lover is thrown to, always followed by a lament; all these has shown to be present in Aeneid's book IV. So, in addition to evincing how epic genre, without losing its formal rigour, subsume other genres, in this case the elegiac one, this article observes how this procedure takes part in both Vergil's intra-narrative and extra-narrative purpose when composing Aeneid. In the first case, if we bear in mind that books I to VI are concerned with the construction of Aeneas' heroic $\tilde{\eta} \theta$ os, the hero's denial in staying together with the queen confirms, once again, his destiny, which is Rome's foundation, that is conventionally of an epic hero - and not of an elegiac lover. As for the second one, it is first important to be aware of Vergil's aim when composing Aeneid, which is to insert Rome's history into a myth, which is the elegiac poem itself. Therefore, Dido's abandonment and her following imprecation in verses 590-640 are used by the poet to justify, even if ironically, Carthaginians' rivalry and violence against Romans throughout the Punic Wars, putting them as the result of a woman's love frustration.
\end{abstract}

Keywords: Aeneid; Book IV; Virgil; epic; elegy; love 


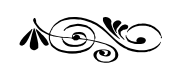

Plus in Amore ualet Mimnermi uersus Homero: carmina mansuetus lenis quaerit Amor

Prop. 1,9,11-2.

No Canto IV da Eneida, Virgílio nos narra o malogrado amor entre Dido e Eneias, desde seus primeiros encantos até seu final, que tem como resultado o suicídio da rainha. Ora, ao fazêlo, o poeta vale-se de algumas tópicas elegíacas, mostrando-se afinado com a concepção do gênero elegíaco tal como ele fora apropriado pelos romanos, principalmente na época de Augusto, em que vemos como principal característica o lamento diante do amor malfadado. Ainda que os elegíacos augustanos, Tibulo, Propércio e Ovídio, confiram, muita vez, ao lamento alguma inclinação irônica, é inegável que há sempre presente a condição de um amante, ou ego, tu, ou ille elegíaco, que ao ser acertado pelas flechas de um Cupido, passa a ser escravo e a sofrer pela sua amada - sua domina, sua puella o que subtrai dela uma possível e futura posição de subserviência amorosa, aliás, o lugar-comum dessa mulher elegíaca é sua condição de comando, relegando ao amado o papel de subserviência a ela. Destarte, procuramos mostrar como Virgílio, ao narrar a paixão de Dido por Eneias e sua subsequente frustração, acaba por inserir passagens fundamentalmente elegíacas na estrutura do poema épico cujos temas são: a paixão e a loucura que acometem a rainha - o que aponta para a subversão do papel feminino no gênero elegíaco -, a ociosidade dos amantes que os faz submergir na nequitia, o rumor sobre o novo casal, e, por fim, o papel da invectiva no discurso amoroso, que apesar de ser invariavelmente tratada em versos iâmbicos, mostra-se também presente em algumas elegias, já que nos parece uma decorrência costumeira da frustração amorosa.

Por outro lado, se é certo que a poesia épica é recusada pela e na poesia elegíaca - e a nossa epígrafe neste caso justifica-se -, dado que ao amante elegíaco, ao ego elegíaco não compete ações de ordem épica, suas guerras são as da alcova. E tampouco o mito heroico, aqui pensamos no enredo, serve ao descompasso rítmico do dístico elegíaco, expressivamente suave, pois que no segundo verso da estrofe lhe é imposta uma dupla quebra de pé métrico, mitigando a gravidade e a dureza do hexâmetro heroico com malemolência e sinuosidade acentuadas no pentâmetro tanto em res quanto em uerba. Por seu turno, a épica oferece largo ambiente para desenvolvimentos de tópicas exógenas, entretanto sem ceder a qualquer inflexão formal, entre as 
tópicas, as elegíacas podem ser aferidas serialmente pelo menos desde Homero - pesamos aqui no episódio de Heitor e Andrômaca cujo amor malfadado é-nos oferecido no Canto VI da Ilíada ou em Apolônio de Rodes nas Argonáuticas ${ }^{3}$ ou Catulo no poema 64 - um epílio -, quando nos pintam Ariadne abandonada por Teseu. Isto sem pensarmos em duas personagens homéricas que, a nosso ver, coadunam-se de forma precisa ao gênero elegíaco latino: Páris e Helena $^{4}$. Assim, podemos pensar que o gênero hexamétrico, bélico ou não, configura-se como gênero que não opera as recusationes genéricas, como ocorre na elegia romana, antes ele subsume outros gêneros, cosendo-os a serviço da tessitura narrativa cujas nuanças são épicas, pois que são complexas, ou complexas, dado que são épicas. A esta subsunção, Gregory Hutchinson ${ }^{5}$ chamou super-genre, isto é, super-gênero, ainda que em seu caso o scholar entreveja, e isto parece-nos razoável, um super-genre hexamétrico, um elegíaco e outro um lírico.

Nesse sentido, a operação da épica como um super-gênero que opera o tema elegíaco, implica questões intra e extratextuais. Assim, mostraremos, também, que a caracterização do amor entre Dido e Eneias como elegíaco é útil tanto para o projeto intranarrativo da Eneida como para o extranarrativo. Explicamos: nos primeiros seis cantos, podemos observar a construção do $\tilde{\eta} \theta$ os heroico de Eneias $^{6}$ e, nesse sentido, o canto IV representaria mais um dos obstáculos que o herói tem de ultrapassar na descoberta de sua própria condição e Eneias, ao abandonar Cartago e sua amante, estaria mais uma vez confirmando os Fados e seu $\tilde{\eta} \theta$ os, que é por si só incompatível com o de amante, analogamente a Heitor ou a Teseu. Há que se lembrar que apenas ao final do canto VI Eneias terá sua formação perfeita, entendendo-se como um herói completo, portanto. Essa função a consideramos como intranarrativa. Já quanto à função extranarrativa, leva em consideração o projeto político, por assim dizer, de Virgílio ao escrever a Eneida, já que o poema serve-se principalmente da inserção da história de Roma, de seu Império, no âmbito mito, ou a inserção do mito no âmbito história de Roma - em ambas as possibilidades o poema perfaz suas funções plenamente. Antes, importa saber que na narrativa intratextual Virgílio procura justificar alguns acontecimentos históricos, entre eles, e é esse que nos importa, a rivalidade entre Roma e Cartago. Curiosamente, a frustração amorosa e o lamento da rainha são elegíacos, embora as mulheres elegíacas nunca estivessem sujeitas ao lamento, mas sim os homens, significa dizer que o amante elegíaco é, por princípio, um infeliz, miser, diante do amor - e daí decorre amiúde uma invectiva na elegia. Virgílio,

\footnotetext{
3 Arg. 4.421-34.

${ }_{4}$ MARTINS, 2017e, pp. 159-206.

5 HUTCHINSON, 2013, pp. 19-34.

${ }^{6}$ MARTINS, 2001, pp. 143-57; MARTINS, 2013, pp. 50-71.
} 
extranarrativamente, parece justificar a ira dos cartagineses, e seu empenho na guerra contra Roma, como resultado de uma antiga frustração amorosa, resultado da ira de Dido contra o troiano - que, como veremos, será tanta que causará o suicídio dela. Nesse sentido, o Canto IV, para além de representar mais uma etapa na constituição do $\tilde{\eta} \theta$ os heroico de Eneias, também justificaria a crueldade bélica dos cartagineses e sua rivalidade com os romanos - que só poderiam ser mesmo resultado de uma grande frustração amorosa, uma tremenda e absoluta ironia política a nosso ver.

No início do canto IV, vemos Virgílio caracterizar Dido:

At regina graui iamdudum saucia cura

Vulnus alit uenis et caeco carpitur igni.
Quanto à rainha, ferida de cega paixão desde muito

Nutre nas veias a chaga e no oculto braseiro se afina ${ }^{7}$

A abertura do canto indica seu constructo. Dido encontra-se tomada pela paixão, que é justamente a primeira e fundamental característica da personagem elegíaca. Mas se é verdade que isso per se não justifica uma referência ao amor na elegia, podemos ver que há a caracterização da afecção dessa paixão como uma "ferida" (uulnus, -eris)s ou seja, como uma marca, uma sequela que distingue o ser apaixonado e dele se apossa, enlouquecendo-o, isto é, o apaixonado é só ferida, é uma só chaga por sinédoque. Vale dizer, ainda que o uso de uulnus seja tópica elegíaca, uma vez que caracteriza o dano causado pelo amor ${ }^{9}$, não podemos deixar de assinalar sua relação com o léxico bélico, dado que pode ser operado como resultado do combate, da luta, da batalha. Na verdade, a própria tópica da militia amoris propicia ou autoriza o uso decoroso do termo. Propércio, por exemplo, vale-se de seu uso por 13 vezes em suas coleções, em 2A, 1,39-46, tratando justamente do decoro dos gêneros propõe:

\footnotetext{
7 VERG. Aen. 4, 1-2. Tradução de Carlos Alberto Nunes.

8 Em Ovídio, portanto na produção poética seguramente posterior à Eneida, temos a utilização do termo em 223 ocorrências, ainda que surja nas Metamorfoses (129 vezes) e em Haliêutica (3 vezes), o que comprova precisamente o campo elegíaco do léxico em questão. Vale dizer que a presença nas Metamorfoses não impede o uso elegíaco nos mesmos moldes a que estamos propondo para a Eneida.

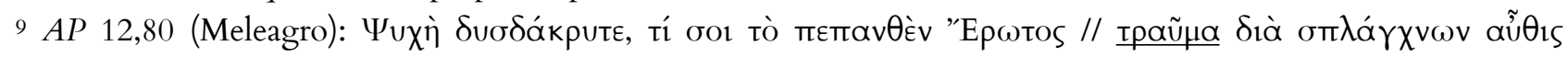

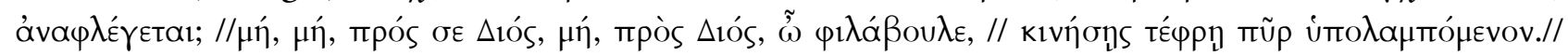

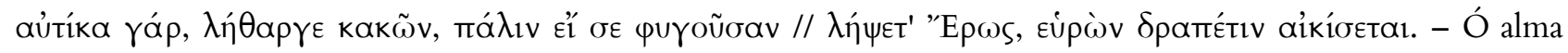
chorosa, por que a ferida de Eros a ti suavizada// inflama-se de novo nas entranhas?// Não, não, por Zeus, não, por Zeus, ó imprudente,// o fogo não para de arder sob as cinzas! //Imediatamente esquece os teus males, se Eros te pegou de novo// Ele irá te torturar escravo como um fugido. (Tradução de Paulo Martins).
} 


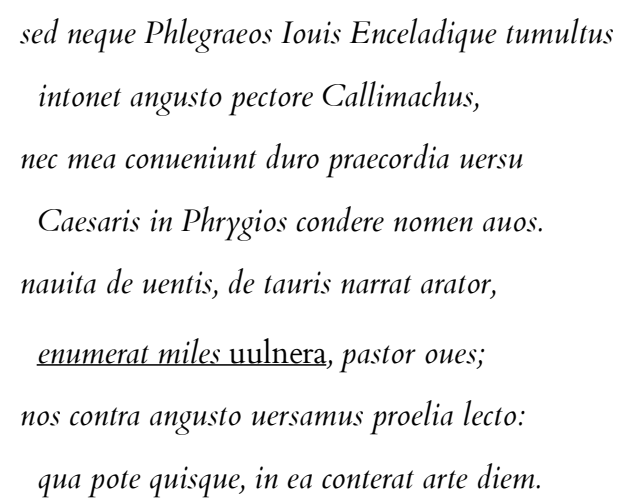

sed neque Phlegraeos Ionis Enceladique tumultus

intonet angusto pectore Callimachus

Caesaris in Phrygios condere nomen auos.

nauita de uentis, de tauris narrat arator,

enumerat miles uulnera, pastor oues,

qua pote quisque, in ea conterat arte diem.

Mas a luta entre Júpiter e Encédalo em Flegra

Calímaco não elevaria com angusto peito,

nem meus sentimentos convêm ao verso grave,

para cantar o nome de César entre avós frígios.

O nauta, sobre os ventos; sobre os touros, narra o agricultor o soldado enumera feridas, o pastor ovelhas.

$\mathrm{Eu}$, de revés, sou versado nas lutas em leito angusto:

Cada um gaste o dia na arte que lhe cabe ${ }^{10}$.

Observa-se que uulnus nesse caso está aplicado ao decoro do gênero épico, mesmo que esteja na elegia. A bem da verdade, à recusatio apresentada em "nem meus sentimentos convém ao verso grave" - épico, portanto -, segue-se a subsunção pelo super-genre épico de outros gêneros hexamétricos, a saber, a épica de viagem (o nauta), o epos didático (o agricultor), a épica de guerra (o soldado) e o hexâmetro bucólico (o pastor) ${ }^{11}$. Refere-se Propércio, a nosso ver, a Virgílio da Eneida, das Geórgicas e das Bucólicas. Contrapõe a esses gêneros o seu fazer poético propondo "sou versado nas lutas em leito angusto" como Calímaco já o fizera com "angusto peito". Logo, ao lutar no leito a refrega da militia amoris, naturalmente, haverá de ser ferido, assemelhando-se, pois, ao soldado virgiliano que enumera suas próprias feridas. Donde poderá contar/cantar pelo decoro do gênero os uulnera de sua guerra particular do tálamo.

O amor de Dido que no segundo verso é apresentado no campo semântico do ignis ${ }^{12}$, evolui ao ser chamado de furor, cujo sentido passa justamente pela ideia de uma doença e/ou loucura que ardet, isto é, abrasa, como nos mostra o verso 101 "ardet amans Dido traxitque per ossa furorem - Dido até os ossos se abrasa de intensa paixão, irrefreável13". De tal paixão, ainda, advém a condição necessariamente miserável e infeliz, como fica claro na passagem do verso 68 "Vritur infelix Dido - Arde a rainha infeliz". Virgílio também a caracteriza como demens, no verso 78, em que diz "Illiacosque iterum demens audire labores - No seu delírio, outra vez quer ouvir os desastres de Tróia". Carlos Alberto Nunes, ao traduzir demens como "no seu delírio", dá a exata medida da condição quase doente do ser apaixonado.

\footnotetext{
10 PROP. 2A, 1, 39-46. Tradução de Paulo Martins. Martins (2017, p. 435).

11 Ver OLIVA NETO, 2013, pp. 41-70.

12 Em Propércio temos 19 ocorrências.

13 VERG., A. 4.101. Tradução de Carlos Alberto Nunes.
} 
O mesmo furor que na elegia programática de Propércio é apresentado como sendo a afecção do ego elegíaco:

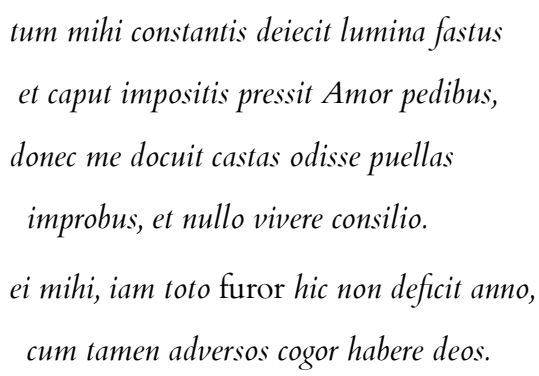

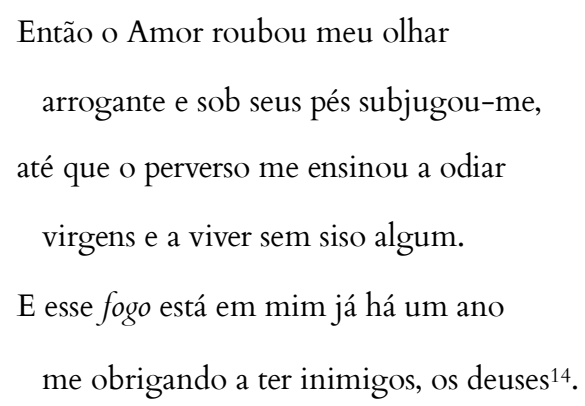

O furor que acomete Dido, faz com que o ego elegíaco em Propércio atue buscando ter o cúmulo da insanidade, os deuses contrários. O fogo da paixão impede que a ação racional se efetive, se perfaça. A ausência de racionalidade movida pela presença do furor, transforma a felicidade no amor na infelicidade anímica. Afinal, ter os deuses contrários só pode levar os pacientes ao suicídio. Está aí delimitada, portanto, a condição miserável (infelix) de Dido, cuja causa é a loucura de amor (furor) que a toma tão fortemente que não só a fragiliza (graui saucia), como também a enlouquece (demens). Tal condição torna-se ainda mais evidente através do símile dos versos 70 ao 73, em que Virgílio compara Dido com uma veadinha atingida por setas (telis), de sorte que um uolatile ferrum de um caçador nela se fixou:

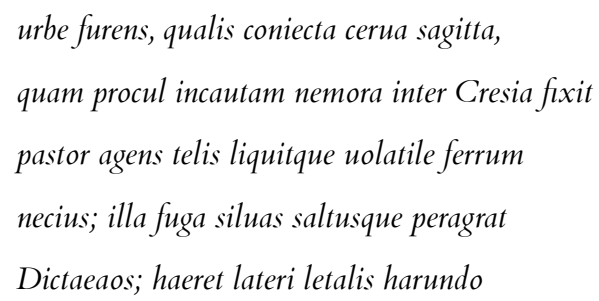

\author{
Sem rumo certo, tal como veadinha nos bosques de Creta \\ que o caçador transfixou com uma flecha, sem que ele consciência \\ então tivesse do fato. O volátil caniço ali fica; \\ corre a coitada, vencendo florestas do Dicte e arvoredos \\ Mas, sempre ao lado encravada, sentindo a fatal mensageira ${ }^{15}$.
}

O símile proposto por Virgílio claramente extraído da poesia didático-cinegética - uma dimensão do epos - interage com a poesia amorosa já que aproxima a imagem do caçador com a

\footnotetext{
14 PROP. 1, 1, 3-8. Tradução de Paulo Martins. Martins (2017, p. 429).

15 VERG. Aen. 4, 69-73. Tradução Carlos Alberto Nunes.
} 
de Cupido, ambos estão munidos de setas, ambos buscam suas presas, ambos produzem uulnus, ambos são de Creta (Cnosia pharetra e Cresia nemora): o primeiro referencialmente, já o segundo figurativamente. Vale dizer que de Creta também vem Vênus. Ocorre, entretanto, que a seta que atinge Dido, não a mata imediatamente como a cerva, antes irá produzir uma série de efeitos e afecções como Propércio operou em 2B,1216 para depois sim levá-la ao suicídio:

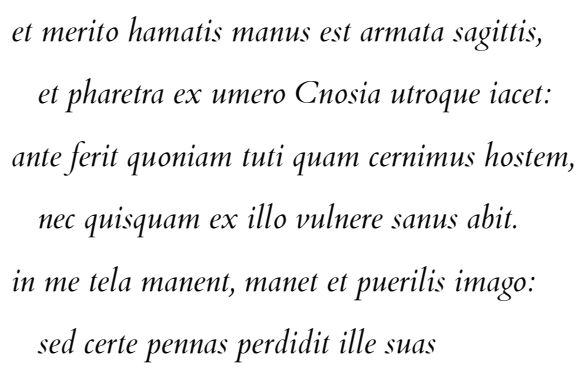

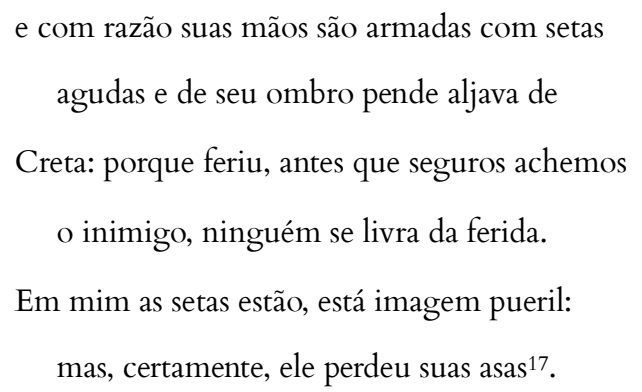

Assim, se simplesmente o amor não era motivo para afirmar categoricamente a caracterização elegíaca de Dido, vemos agora que esse amor recebe um tratamento tipicamente dado ao amante elegíaco, que é também acometido por uma paixão muito forte, diante da qual se fragiliza. A elegia 1,1 de Propércio, nesse sentido, possui passagens exemplares para a caracterização do amante na elegia, na qual refere-se ao ego elegíaco, apaixonado, como me miserum (eu miséravel) e, adiante, dirá que "et mihi iam toto furor hic non deficit anno18. Vemos, portanto, que no poema 1,1, prescritivo por excelência, Propércio constrói o $\tilde{\eta} \theta$ os elegíaco, como também fará em tantas outras elegias. Além disso, dirá aos seus amigos para ajudá-lo: "procurem ajuda para meu doente coração - quaerite non sani pectoris auxilia"19, o que por fim completa a caracterização de Dido feita por Virgílio ao início do canto IV: ela, como o ego elegíaco, é tomada pelo furor (furor) e diante dele torna-se miserável (misera) e infeliz (infelix), pois está ferida (saucia) ou doente (non sani, demens) de paixão. Ovídio, na elegia 1,2 de Amores, também elucida a condição miserável e enlouquecida do amante ao ser atingido pelo amor: "Mens Bona ducetur manibus post terga retortis/ Et Pudor et castris quidquid Amoris obest" - Bomsenso as mãos suspensas leva atrás de si Pudor e o que os quartéis de amor afronta ${ }^{20}$. O elegíaco,

\footnotetext{
16 Ver MARTINS, 2017b, pp. 175-92; MARTINS, 2013, pp. 70-87.

17 PROP. 2B, 12, 9-14; MARTINS, 2013, p. 80.

18 PROP. 1,1,7.

19 PROP. 1,1, 26. MARTINS, 2017a, p. 429.

${ }^{20}$ OV. Am. 1,2,31-2. Tradução de Guilherme Duque.
} 
então, afirma que o Bom-senso e o Pudor seguirão em um cortejo e deixarão o amante mostrando e confirmando, mais uma vez, que quem é tomado pelo amor vê-se abandonado de uma mente sã e do pudor. Esse último, por fim, Virgílio diz ter abandonado Dido, no verso 55 "soluitque pudorem". Propércio nos diz, por seu turno, em forma de aconselhamento: "vos, ubi contempti rupistis frena pudoris,/ nescitis captae mentis habere modum" - Vocês, quando desconsideram os freios do pudor desprezível, desconhecem haver os modos na mente cordata ${ }^{21}$.

Nesta primeira caracterização de Dido apaixonada, também vemos Virgílio introduzir outro sintoma do amante elegíaco: a negligência e a ociosidade que dela advêm. No gênero elegíaco, os deveres de cidadão, fundamentalmente a guerra e a vida pública, são negligenciados e substituídos pelo cuidado com a amada. Nada mais importa para o amante se não a sua puella, e, nesse sentido, é de se entender que, para além de renunciar à vida pública, o amante passa seu tempo no ócio, na devassidão (nequitia) - ou, enfim, no colo de sua amada:

It is idleness because the lover avoids the military and political activities engaged in by the good Roman. Such idleness was called by traditional terms, ignavia, inertia, segnitia, desidia, nequitia or otium. (...) for it describes the lover's loss of fides, virtue, and all the other good qualities in love22.

Em Ovídio, no poema 1,9 dos Amores, vemos que há a defesa da condição apaixonada do ego elegíaco, negando, de maneira irônica, que seja efetivamente ociosa - já que caberia ao amante travar duras guerras na cama com sua amada. Assim, desta ociosidade, vemos surgir no gênero elegíaco duas importantes e recorrentes tópicas: militia amoris e seruitia amoris. $\mathrm{O}$ amante torna-se escravo de sua amada, abdicando de seus deveres públicos, principalmente o da guerra, afirmando que já é um soldado no campo de batalha amoroso, em que tem de lutar contra as duras leis de sua domina:

Militat omnis amans, et habet sua castra, Cupido

Attice, crede mihi, militat omnis amans.

Quae bello est habilis, Veneri quoque conuenit aetas

Turpe senex miles, turpe senilis

Quos petiere duces animos in milite forti amor.

Hos petit in socio bela puella uiro.

\footnotetext{
21 Prop. 3,19, 3-4. Tradução de Paulo Martins.

22 SAYLOR, 1986, pp. 73-7.

${ }^{23}$ OV. Am. 1, 9, 1-6. Tradução de Guilherme Duque.
}

Milita todo amante, e tem quartéis Cupido; Ático, crê, milita todo amante.

A idade própria à guerra a Vênus também serve; torpe é soldado velho e amor senil!

O vigor que ao soldado o general exige, este exige ao parceiro a bela moça ${ }^{23}$. 
A negligência e o ócio, ao que parece, também acometem Dido ao apaixonar-se por Eneias. Nos versos 86 ao 89, embebendo-se do amor e das fantasias que dele decorrem, esquece de alguns de seus deveres como rainha:

\author{
Non coeptae assurgunt turres, non arme iunentus \\ Exercet portusue aut propugnacula bello \\ Tuta parant, pedent opera interrupta, minaeque \\ Murorum ingentes aequataque machina caelo
}

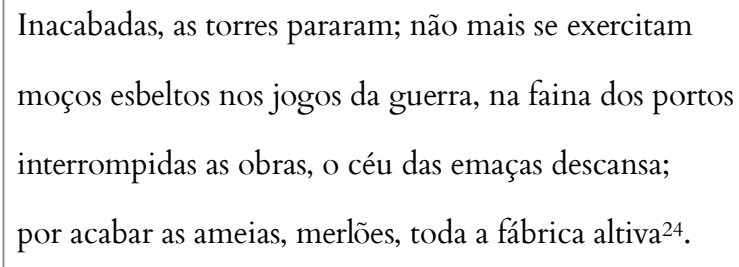

Até aqui, todavia, Dido ainda não havia de fato começado a se relacionar com Enéias, o que ocorre precisamente no verso 160, em que ela e Enéias, por força das tramas de Juno e Vênus, protegem-se da chuva em uma caverna e lá ficam presos. Dessa maneira, Virgílio já nos atenta que este será o início dos dias letais da rainha (ille dies primus leti), o princípio de seus males (primusque causa fuit ${ }^{25}$ ) - retomando, aqui, a já feita caracterização de Dido como infeliz e miserável, característica essa que é comum ao amante no gênero elegíaco, como vimos no início deste texto.

A seguir, temos a introdução de um novo elemento elegíaco, que é a própria Fama - cuja personificação é operada precisamente por Virgílio. A fama, ou rumor, acaba por desempenhar na elegia um papel fundamental, pois ela é a responsável por espalhar a condição do amante alienado de seus deveres, ocioso, infeliz e servo de uma mulher, para a cidade. É consequência do rumor a perda da reputação do amante. Em Catulo 5, já podemos observar a presença do rumor quando diz "rumoresque senum serueriorum/omnes unius aestimemus assis" - E aos rumores dos velhos mais severos/voz nem vez vamos dar ${ }^{26}$. Em Propércio, observamos diversas vezes a referência a mala fama que Cíntia o causou: a) "Dum tibi deceptis augetur Fama puellis" Enquanto sua fama cresce com meninas iludidas27; b) "Et dicor lecto iam grauis esse tuo" - E já

\footnotetext{
24 Tradução de João Angelo de Oliva Neto.

25 VERG. $A .4$, 169-70.

26 Tradução de João Angelo de Oliva Neto.

27 PROP. 1,13,5. Tradução de Paulo Martins. Martins (2017c).
} 
sou tido como um traste em teu leito ${ }^{28}$; e c) "Hic mihi conteritur nitae modus, haec mea Fama est"Meu modo de vida assim decorre, esta é minha fama ${ }^{29}$.

É justamente essa má fama que Virgílio personifica e que carrega consigo, novamente, a ideia da ociosidade dos amantes. Essa fama propaga que tanto Dido como Enéias agora encontram-se "no luxo torpe embebidos"30" (nunc hiemem inter se luxu, quam longa, fouere) e que passam os dias "cuidando de diversões, olvidados dos reinos, dos próprios deveres" (regnorum imemores turpique cupidine captos) ${ }^{31}$. É justamente essa fama que chega aos ouvidos de Jarbas, que, por sua vez, a passará para Júpiter.

Bem, faz-se necessário notar que é precisamente no momento em que Eneias passa a receber características elegíacas, em especial quanto à ociosidade a qual levou o amor, em que vemos a narrativa se valer de Júpiter e seu mensageiro, Mercúrio ${ }^{32}$, para alertá-lo da necessidade de partir e fundar Roma - em suma, de seu destino. É exatamente nisso que consiste o alerta de Mercúrio:

Continuo inuadit: 'Tu nunc Carhaginis altae' fundamenta locas pulchramque uxorius urbem Exstruis, heu regni rerumque oblite tuarum?
Pronto o interpela: "Que fazes? As bases assentas possantes da alta Cartago, com o teu mulherengo pendor para as coisas da antiga pátria de todo esquecido e dos teus interesses?33

Percebe-se, então, que Mercúrio aponta justamente para o fato de que Eneias não nasceu para um "mulherengo pendor", que seria tipicamente elegíaco, mas para a fundação de Roma, para feitos maiores - que é fundamentalmente a matéria dessa narrativa épica. O ̃̃ $\theta$ os elegíaco consiste na renúncia às armas, na vida ociosa, na servidão amorosa, no lamento. Se lembrarmos de Aristóteles e sua divisão dos gêneros quanto ao objeto da imitação, em superior, inferior e igual a nós, temos a exata medida de que a elegia é, em verdade, um gênero que trata de pessoas iguais a nós. A posição média da elegia é comentada por João Angelo Oliva Neto,

\footnotetext{
28 PROP. 2,24,20. Tradução de Paulo Martins.

29 PROP. 1,7,9. Tradução de Paulo Martins (2017c).

${ }^{30}$ VERG. $A .193$. Tradução de Carlos Alberto Nunes.

31 VERG. $A$. 194. Tradução de Carlos Alberto Nunes.

32 Ver MARTINS, 2017d, p. 43.

33 VERG. Aen. 4, 265-7. Tradução de Carlos Alberto Nunes.
} 
que, ao referir-se à poesia de Mimnermo, cuja influência foi determinante na elegia erótica romana, afirma que:

(...) com dizer respeito antes à pessoa do que à coletividade, isto é, por referir-se a menos pessoas e por se lhes referir na sua condição particular, não é ação igual à de sábio nem à de herói, mas é de alguém como nós, igual a nós ${ }^{34}$.

como de fato ocorre na elegia em Roma, se pensarmos que Propércio, Ovídio e Tibulo, por exemplo, são construções verossímeis de jovens romanos que, se não históricos, certamente possíveis de serem encontrados naquela sociedade, que relatam sua condição particular de amantes e se inserem em um contexto romano partilhado pelos leitores ${ }^{35}$. Além disso, a própria matéria amorosa e seus sofrimentos já não seriam considerados elevados, pois (como bem sabe Dido!) nos deixa não somente feridos e vulneráveis, mas também dominados por e servos de outrem - que não seriam, a princípio, características desejáveis em um herói. E, nesse sentido, ainda que Dido seja a rainha de Cartago, ela acaba aproximando-se de nós através do amor que sente, que a rebaixa, enquanto Eneias jamais poderá fazê-lo:

It is clear that his aim is to represent Aeneas not as the victim of love's madness but as a temporary participant in it, one who becomes involved in amour but is ultimately able to reject it for his goals as leader of the Trojans. He makes furor a test of balance and self-possession for Aeneas, a test that his hero, unlike the traditional lover, succeeds in. 36

A leitura do excerto de Saylor aponta exatamente para a impossibilidade de Eneias ser caracterizado como um amante tipicamente elegíaco, posto que ele é um herói, destinado pelos Fados a fundar Roma: é, portanto, um homem superior a nós, que não poderia resignar-se perante ao amor. Ainda, é necessário considerar que a recusa de Eneias para o amor, que se dará depois do aviso de Mercúrio, situa-se precisamente na primeira parte do livro, destinada à própria constituição de seu caráter heroico. Nunca é demais lembrar que os primeiros seis cantos da Eneida não narram somente uma viagem espacial, de Tróia a Roma, mas também uma viagem que permite o próprio reconhecimento do personagem como herói, visto que Eneias não era reconhecido como tal até então ${ }^{37}$ - por ser, como chamou João Angelo Oliva Neto ${ }^{38}$,

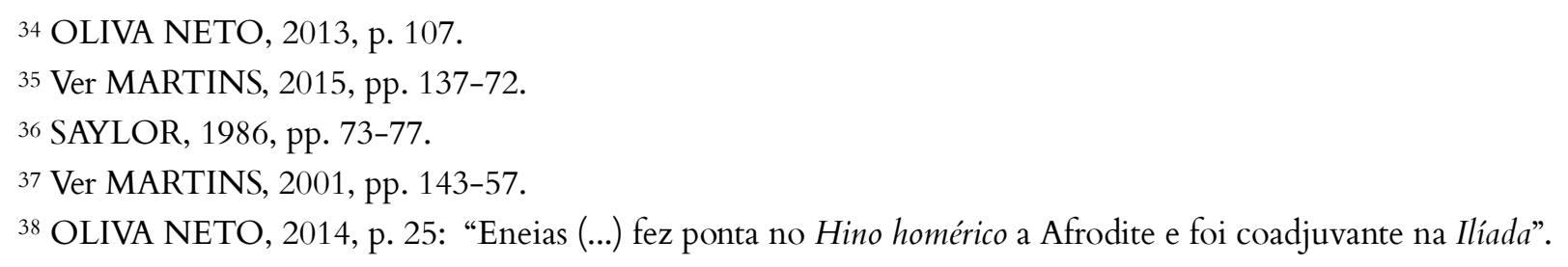


“coadjuvante" nas passagens literárias em que esteve presente. Se, então, no canto I, ao se reconhecer pintado nas paredes do templo de Juno, há a primeira indicação do caráter heroico do personagem ${ }^{39}$, que se encontra retratado entre os homens superiores a nós, como Aquiles e Heitor, igualando-se a eles, vemos no canto IV mais uma etapa desta constituição, que se dá precisamente pelo abandono necessário de Dido e a recusa em se tornar um "soldado do amor".

Tal recusa, portanto, é também uma afirmação do caráter superior de Eneias, cujo destino é a realização de feitos elevados e, por conta disso, não deve ser conhecido através da mala fama, através de sua relação amorosa - mas sim pela bona fama, que é aquela que o herói épico busca com seus feitos, é a própria glória (o k $\lambda$ Éo૬). Assim, ainda que se oblitere deste seu destino heroico enquanto está nos braços de Dido, Júpiter o relembra para o herói, rememorando-o da própria glória que o espera: "si te nulla mouet tantarum gloria rerum" - Se não te move a ambição do porvir prometido, a esperança ${ }^{40}$, ou mais propriamente: "se nenhuma glória de tamanha monta te move"41.

Os Fados não são outros senão os de Eneias como herói-fundador de Roma. Por isso mesmo, ao despedir-se de Dido, ele diz "não busco a Itália por gosto" (Italiam non sponte sequor ${ }^{42}$ ), precisamente porque é seu destino fundar Roma - e, para tanto, é necessário que se entenda como herói, coisa que o Canto IV, ao mostrar o herói abandonando a posição de amante, mais uma vez confirma.

Para elucidar, ainda, a diferença entre o 询os épico e o elegíaco, seria de grande valia relembrar a elegia 1,1 de Ovídio, em Amores, na qual diz que estivera disposto a narrar grandes feitos, referência ao gênero épico, mas foi acertado pela flecha do Cupido, restando-o apenas a possibilidade de fazer versos com 11 pés:

\footnotetext{
39 MARTINS, 2001, pp. 143-57; MARTINS, 2013, pp. 48-69.

40 VERG. A. 4, 272. Tradução de Carlos Alberto Nunes.

41 Tradução nossa.

42 VERG. A. 4, 361.
} 


Arma graui numero uiolentaque bella parabam
Edere, materia conveniente modis
Par erat inferior uersus, risisse Cupido
Dicitur atque unum surrupuisse pedem.
(...)
Sex mihi surgat opus numeris, in quinque residat!
Ferrea cum uestris bella ualete modis!
Cingere litorea flauentia tempora myrto
Musa, per undenos emodulanda pedes!

Arma graui numero violentaque bella parabam

Edere, materia conveniente modis

(...)

ue residat!

Musa, per undenos emodulanda pedes!

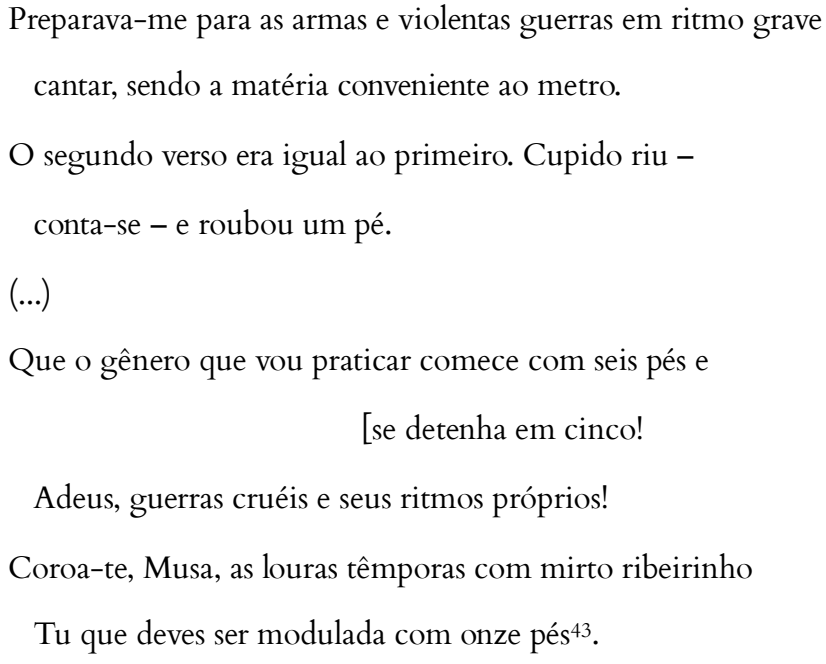

Ovídio, valendo-se da diferença métrica entre os gêneros, a saber, de apesar de serem ambos hexamétricos, o elegíaco é duplamente catalético, ou seja, tem um pé métrico a menos, também acaba por retratar a diferença da matéria: ora, quando o Cupido rouba um pé do verso, acaba por rebaixar a própria matéria poética, que deixa de ser aquela destinada a narrar feitos de homens superiores a nós, heróis e deuses, e torna-se a responsável por narrar o amor e suas consequências, que são próprios de homens iguais a nós. Faz-se claro, então, o porquê de Eneias ter de abandonar Dido - ao fim e ao cabo, a resposta está óbvia no próprio motivo fundador da Eneida: é preciso fundar Roma. O soldado do amor, ou o herói amante, outro gênero se preocupará em retratar, precisamente o gênero elegíaco.

Todavia, se não cabe ao herói a condição elegíaca, não é isso que vemos em Dido. Observamos Virgílio reunir na personagem, ao início, características deste gênero, como a doença de amor, a infelicidade, a má fama, a ociosidade. Além da própria antecipação do infortúnio do seu amor, no momento em que o confessa para Ana, sua irmã:

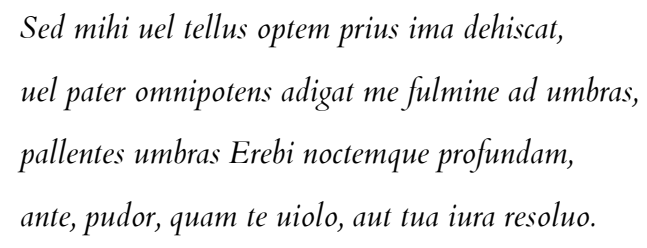

Sed mihi uel tellus optem prius ima dehiscat, uel pater omnipotens adigat me fulmine ad umbras, pallentes umbras Erebi noctemque profundam, ante, pudor, quam te niolo, aut tua iura resoluo.

Antes, porém, escancare-se a terra no abismo eu mergulhe ou o padre sumo com um raio me atire no reino das sombras pálidas, no Érebo logo eu baixando, até a noite profunda, Do que, pudor, eu violar-te e infringir teus preceitos sagrados ${ }^{44}$.

\footnotetext{
43 OLIVA NETO, 2013, p. 124.

${ }^{44}$ VERG. Aen. 4, 24-7. Tradução de Carlos Alberto Nunes.
} 
De alguma maneira, então, Dido prevê que será atirada (adigat) às sombras (ad umbras) com esse amor, caracterizando-o, assim, como um amor malfadado, que é mister na elegia romana augustana. Não obstante, o $\tilde{\eta} \theta$ os elegíaco da rainha é ainda acentuado no momento em que descobre a partida de Eneias, no qual podemos observar muito claramente a configuração de um lamento diante da descoberta da ruína de seu amor. Embora não haja consenso sobre sua acepção primeira, há grandes indícios de que o gênero elegíaco sempre esteve, desde a Grécia Arcaica, associado ao lamento, característica que foi mantida pelos elegíacos romanos. João Angelo Oliva Neto, ao falar da elegia arcaica diz que:

O discurso exortativo agregou-se de tal modo ao gênero elegíaco (...) que a elegia se independeu da motivação fúnebre primeira, para tornar-se por excelência espaço de exortação, embora paralelamente tenha continuado a ser o que era na origem, isto é, tenha continuado a ser lamento fúnebre e qualquer lamento ${ }^{45}$.

E, mais adiante, sobre a elegia romana, dirá que: "Desnecessário é dizer a esta altura que em todos os quatro poetas os amores, maiormente malogrados, são motivo de lamento, mais desesperado ou mais resignado"46.

Ora, o que faz Dido ao encontrar Eneias após a descoberta de sua partida, do verso 305 ao 330, se não um lamento? Nele, inclusive, podemos encontrar novamente algumas das

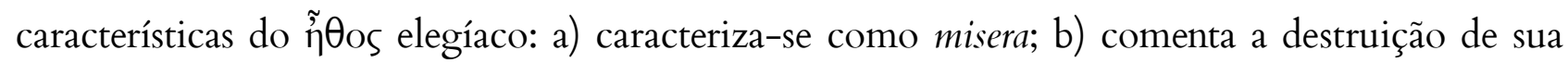
reputação por conta do amor vivido, a mala fama (qua sola sidera adibam/ fama prior); c) afirma ter perdido o pudor, característica não só do ego elegíaco bem como da puella elegíaca (extinctus pudor et), e, por fim, d) associa o amor e a morte, ao se chamar de moribunda (cui me moribundam deseris, hospes?). Esse lamento é comum a elegias romanas, dentre as quais podemos destacar a 1,18, de Propércio, em que diz ter encontrado um lugar calmo para os lamentos, onde poderá expressar a dor ${ }^{47}$, e a 1,3, em que vemos uma inversão do agente do lamento, que passa do ego elegíaco para a própria puella, vejamos:

\footnotetext{
45 OLIVA NETO, 2013, p. 88. Grifo nosso.

${ }^{46}$ OLIVA NETO, 2013, p. 123. Grifo nosso.

47 PROP. 1,18,1-3: Hac certe deserta loca et taciturna quarenti/et uacuum Zephyri possidet aura nemus./ Hic licet ocultos profere impune dolores.
} 


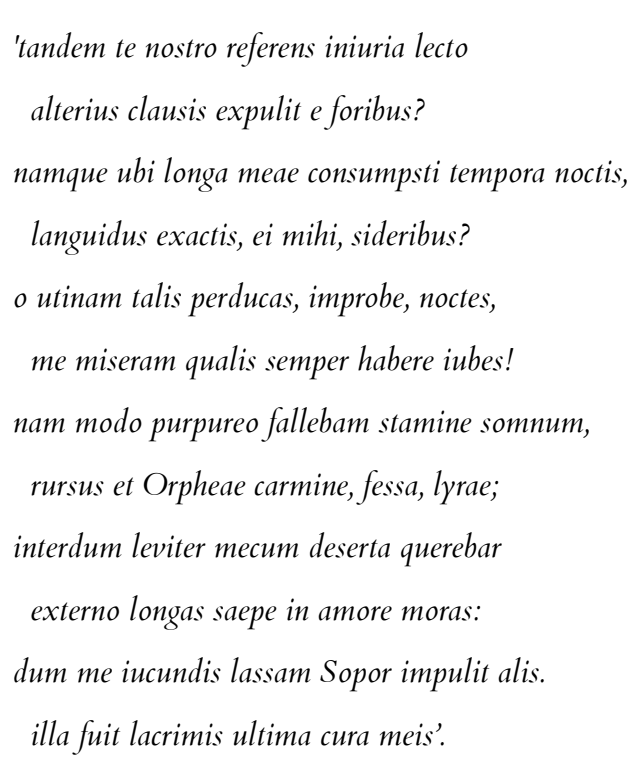

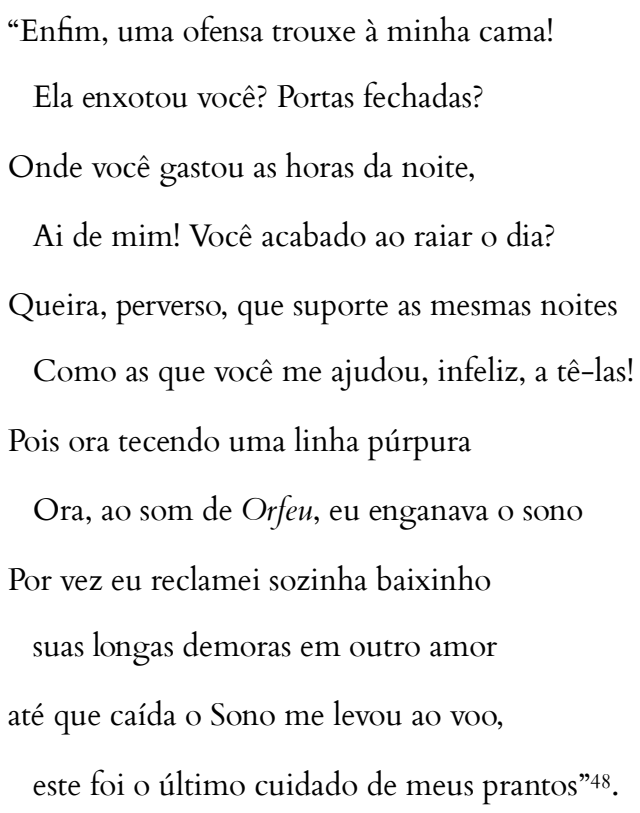

Vemos, aqui, que Cíntia reclama seu abandono para Propércio, como o faz Dido - vale notar que em ambos os casos há a introdução de um vocativo pejorativo, já que a rainha chama a Eneias de perfide e Cíntia chama a Propércio de improbe, bem como o retrato da própria condição de abandono, que é a de misera. Ademais, a partir da leitura deste trecho, podemos tirar outra característica elegíaca que também vemos emergir da figura de Dido: a imprecação, que fica claro nos versos em que diz "O utinam tallis perducas, improbe, noctes/ me miseram qualis semper habere iubes". João Angelo Oliva Neto, ao comentar este procedimento em Ovídio, afirma que:

Ovídio insere a matéria e a elocução do iambo, praticado, talvez inventado, por Aquíloco de Paros. Com fazê-lo, pratica a poikilia, "a matização", no gênero elegíaco, que passa então a possuir algo que não the pertence, a imprecação, a maldição (...) e a invectiva pessoal49.

É precisamente a imprecação e a invectiva que faz Dido diante da recusa de Eneias em permanecer em Cartago. Do verso 590 ao 640, evoca Júpiter, o Sol, Juno, Hécate e as Fúrias, proferindo inúmeras "maldições" a Eneias, desejando-lhe a ruína. Ainda, antevendo a vontade irreversível dos Fados, de que Eneias funde Roma, deseja-lhe as mais duras batalhas ao pisar no solo prometido. É primordial observar a imprecação do verso 625 ao 627 :

\footnotetext{
48 PROP. 1, 3, 35-46. Tradução de Paulo Martins.

49 OLIVA NETO, 2013, p. 132.
} 
nullus amor populis, nec foedera sunto

Exoriare aliquis nostris ex ossibus ultor

Qui face Dardanios ferroque sequare colonos
Nenhuma aliança jamais aproxime os dois povos imigos

Há de nascer-me dos ossos quem possa vingar-me esta afronta

com ferro e fogo, quem limpe o meu nome com sangue dardânio ${ }^{50}$

Para além da caracterização elegíaca de Dido, a imprecação que a rainha realiza nestes versos, e nos anteriores, são construídos por Virgílio justamente em função de seu projeto extranarrativo comentado no início desta análise, a saber, o de inserir a história romana no mito. Virgílio parece ter escrito a Eneida tendo como um dos principais objetivos conferir uma autoridade mítica para o poder do Imperador Augusto e, por que não?, para o próprio império romano. Além de estabelecer a relação divina da família Iulo, que remontaria ao próprio Eneias, sendo ele, por sua vez, descendente de Vênus, Virgílio vale-se de um fato histórico recente na história romana, a guerra contra os Cartagineses (ou Guerras Púnicas), justificando-a através do mito, que é a própria Eneida. Parece, enfim, explicar a histórica rivalidade do povo romano contra Cartago, e a violência e força cartaginesa na guerra, que durou, vale dizer, quase um século, a partir de um desejo de vingança fundado pela frustração amorosa. Nesse sentido, o retrato de Dido a partir de convenções genéricas da elegia (mísera, ferida, infeliz, insana, ociosa, irada) parece também estar em função do projeto de Virgílio ao escrever a Eneida, que é justamente o estabelecimento da história romana no mito. Afinal, ao que parece, a ira de um amante abandonado é imensa, como bem demonstrou a poesia elegíaca e a própria poesia iâmbica- e é exatamente dessa premissa que Virgílio se vale para justificar o empenho dos cartagineses na luta contra os romanos.

Finalmente, então, vemos que Virgílio mostra-se versado nas convenções do gênero elegíaco e se vale delas no Canto IV tanto como um fator determinante na própria narrativa de Eneias, que mais uma vez terá seu $\tilde{\eta} \theta$ os heróico garantido a partir da confirmação de seu destino, como também no seu projeto extranarrativo, isto é, o de inserir o Império Romano, e seu Imperador, no mito da fundação de Roma. Com isso, acaba por operar, ele mesmo, uma poikilia dentro do gênero épico, demonstrando ao fim e ao cabo que se o que se pretende é falar de um amor, ainda mais malogrado, deve-se recorrer à certas características do gênero que primordialmente trata desta matéria, que é, sim, o elegíaco.

\footnotetext{
${ }^{50}$ VERG. Aen. 4, 625-7. Tradução de Carlos Alberto Nunes.
} 


\section{Referências Bibliográficas:}

DUQUE, G. Do pé à letra: Os amores de Ovídio em Tradução Poética. 2015. Dissertação do Programa de Pós-Graduação em Letras. Vitória: Universidade Federal do Espírito Santo, 2015.

HUTCHINSON, G. "Genre and Super-Genre”. In: Generic Interfaces in Latin Literature. Berlin, Boston: De Gruyter: 19-34, 2013. Retrieved 23 Sep. 2017, https://doi.org/ 10.1515/9783110303698.19.

MARTINS, P. “Eneias se reconhece”. Letras Clássicas, 5: 143-157, 2001. doi:http://dx.doi.org/ 10.11606/issn.2358-3150.v0i5p143-157

MARTINS, P. Pictura Loquens, Poesis Tacens: limites da representação. Tese de Livre Docência, Faculdade de Filosofia, Letras e Ciências Humanas, Universidade de São Paulo, São Paulo, 2013. Recuperado em 2017-09-23, de http://www.teses.usp.br/teses/disponiveis/ livredocencia/8/tde-19112015-181808/

MARTINS, P. O jogo elegíaco: fronteiras entre a cultura material ou intelectual e a ficção poética. Nuntius Antiquus, 11(1), 137-172, 2015. Recuperado de http:// www.periodicos.letras.ufmg.br/index.php/nuntius_antiquus/article/view/8539

MARTINS, P. "Propércio Redivivo". In: Livro: Revista do Núcleo de Estudos do Livro e da Edição (NELE), v. 6: 426-41, 2017a.

MARTINS, P. "Ekphrasis, Digression and Elegy: The Propertius' Second Book". Classica Revista Brasileira de Estudos Clássicos, 30.1: 175-192, 2017b. doi:http://dx.doi.org/ 10.24277/classica.v30i1.437.

MARTINS, P. "Propércio Recidivo". Translatio, v. 14, 2017c. (forthcoming).

MARTINS, P. Augusto como Mercúrio enfim. Revista de História, 176: 01-43, 2017d. doi: http://dx.doi.org/10.11606/issn.2316-9141.rh.2017.116333

MARTINS, P. Tum longas condimus Iliadas: a Helena de Propércio. Archai 21, sep.-dec., p. 159-206, 2017e. doi: https://doi.org/10.14195/1984-249X_21_5

Oliva Neto, J. A. Dos Gêneros da Poesia Antiga e Sua Tradução em Português. 2013. Tese de Livre Docência - Universidade de São Paulo, São Paulo, 2013.

OLIVA NETO, J. A. "Introdução”. In: Eneida. Tradução de Carlos Alberto Nunes; organização, apresentação e notas de João Angelo Oliva Neto. São Paulo: Editora 34, 2014.

SAYLOR, C. "Some Stock Characteristics of the Roman Lover in Vergil, Aeneid IV". Vergilius. Vol. 32: 73-7, 1986.

VIRGÍlLIO. Eneida. Tradução de Carlos Alberto Nunes; organização, apresentação e notas de João Angelo Oliva Neto. São Paulo: Editora 34, 2014.

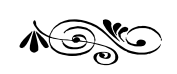

